IJBPAS, April, 2018, 7(4): 406-420

ISSN: 2277-4998

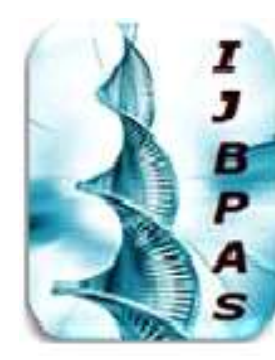

International Journal of Biology, Pharmacy

and Allied Seiences (IJBPAS)

'A Bridge Betusen Caboratory and Qqudo'

WwW.ibpas.com

\title{
FUNDAMENTAL STUDY OF EFFECT DUAL FEED ULTRASONIC SPRAY TECHNIQUE ON CHARACTERISTICS OF P3HT: PCBM BULK-HETEROJUNCTION
}

\author{
N. I. ASHOUR \\ Department of Physics, College of Science, University of Kerbala, 56001 Karbala, Iraq
}

*Corresponding Author: N. I. Ashour: Nabeel.ashoor@uokerbala.edu.iq

Received 26 ${ }^{\text {th }}$ Oct. 2017; Revised $1^{\text {st }}$ Dec. 2017; Accepted 29 ${ }^{\text {th }}$ December 2017; Available online $1^{\text {st }}$ April 2018

\section{ABSTRACT}

In this study the novel Dual Liquid Feed Ultrasonic Spray Method for arrangement of P3HT: PCBM Bulk-heterojunction dynamic layer in Organic Solar Cells. The benefits of this approach over the typical single bolster way are talked about. Impact of different process parameters on the auxiliary, electrical and optical properties of the mass heterojunction of P3HT: PCBM has been exhibited. The appropriateness of the dynamic layer for its application in OSC has been contemplated utilizing consistent state photoluminescence spectroscopy. The dual feed ultrasonic spray technique for the deposition of active layer with Chlorobenzene: Chlorobenzene, Dichlorobenzene: Dichlorobenzene and Chlorobenzene: Dichlorobenzene solvents combinations for donor/acceptor material are used in this present research work. In this research work, tip of the ultrasonic nozzle is worked at ultrasonic recurrence i.e. $120 \mathrm{kHz}$ for utilized nozzle ultrasonic recurrence flag is produced utilizing the ultrasonic recurrence generator and completed through the ultrasonic broadband link to the ultrasonic nozzle. For exact arrangement conveyance to the ultrasonic nozzle two liquid pumps are utilized for the arrangements of contributor furthermore, acceptor materials independently. Both the liquid pumps are controlled by independent pump controllers. The pumps are synchronized with each other so arrangement can be splashed with every conceivable blend of On-Off cycles of individual pumps. To store the film at wanted temperature substrate were put on the hot plate. PID temperature controller was utilized for exact control on the substrate temperature. It is observed that the dual liquid feed ultrasonic technique has been effectively established for fabrication of P3HT: PCBM active layer deposition.

Keywords: Dual Feed Ultrasonic Spray method, P3HT: PCBM, Bulk-Heterojunction 


\section{INTRODUCTION}

Today we are satisfying our vitality necessities utilizing the accessible fossil powers, nuclear vitality and other regular vitality sources. Accessibility of the characteristic assets is constrained and will debilitate. Along these lines, the world is confronting the issue of vitality emergency. Frameworks as of now utilized for vitality creation are most certainly not dependable in ecological perspective; they are likewise unsafe to the human being and living life form on the earth because of emanation of green house gases like $\mathrm{CO}$ also, $\mathrm{CO} 2$. The commitment of $\mathrm{CO} 2$ in earth's environment in the start of mechanical upheaval was 280 ppm (Parts/Million) and in May 2012 as revealed by Globa Observing Division, Earth System Research Laboratory of National Oceanic and Barometrical Administration, it is $396.78 \mathrm{ppm}$ and that is $2.62 \mathrm{ppm}$ more prominent than esteem announced one year back in May 2011 (394.16 ppm [1]). All assets that are utilized as a part of the warm power stations, ventures and transportation frameworks produces green house gasses, which are the significant reason to an Earthwide temperature boost. The expansion in centralization of green house gases is causing the ascent in mean surface temperature. Contingent upon future outflow situations and the genuine atmosphere affectability, it is anticipated that there will be ascend by another $0.6-7.0 \mathrm{oC}$ by the year 2100 [2]. Another for the most part utilized vitality source is Nuclear Power; known for its effectiveness what's more, capacity to give enormous amount of vitality through nuclear parting. Be that as it may, this vitality source is hazardous to the general population living near atomic power stations; it causes the hereditary issue in the prospective ages, if there should be an occurrence of atomic mishap life taxicab influenced in many square miles region. In this manner, Japan which is third biggest economy on the planet close down all working atomic power station in. Right now there are numerous procedures utilized as a part of research center scale gadget manufacture and testing of natural sunlight based photovoltaic cells, for example, Spin covering, Inkjet printing, Pizo-electric printing, Air brush printing, recently developed ultrasonic shower furthermore, double nourish ultrasonic shower procedure.

\section{SPIN COATING:}

Spin Coating is the most generally utilized statement strategy for research center scale creation and testing of natural sunlight based photovoltaic cells. Be that as it may, it 
isn't at risk for modern scale move to-move creation of photovoltaic cell, in the meantime not moderate regarding material use, particularly when the underlying material is costly. This is on account of just 3-5\% material is used for testimony reason and staying material is discarded amid the turn covering process because of radiating drive. Figure 1 displays schematic spin Coating approach [3].

\section{INKJET PRINTING}

Inkjet printing in hardware generation has pulled in significant consideration for an extensive variety of utilizations since it is an earth cordial and low cost strategy [1]. In any case, to utilize this system for affidavit, material requires a few particular properties like high substance strength, low-temperature processability. Inkjet printing has applications going from designing printed circuit sheets to level board shows and photovoltaic. Piezoelectric drop-on-request inkjet is a perfect procedure for the exact affidavit of picoliters of fluid materials. When planning inks for inkjet printing, the organization and character of the arrangement, statement exactness and properties of the resultant film are exceedingly delicate to spout outline and the waveform connected to the piezoelectric component. Inks with Newtonian viscosities permit more control of the parameters required for spout outline. Polymeric serious inks require substantial weakening, high dissolvability, low unpredictability and adequate spout surface associations to limit stopping up. These basic parameters must be advanced to take into consideration appropriate drop arrangement, precision and ceaseless film development. Once an ink has been created, inkjet printing empowers exact material testimony, fast prototyping, boundless layering, and high throughput. Inkjet is extensively utilized as a part of the creation and testing of thin film transistors, polymer light emitting diodes (LED) (LED) what's more, shows [4]. Schematic diagram of inkjet printer head is exhibits in figure 2 .

\section{SPRAY METHOD}

To the extent the testimony of polymer thin movies by shower technique is concerned, Tadahiro Echigo et al have revealed pneumatic splash affidavit of natural thin movies at environmental weight for natural electroluminescent gadget manufacture [3]. Katsuhiko Fujita et al likewise proposed a novel shower affidavit strategy for polymer thin film readiness [4]. Xiaoliang $\mathrm{MO}$ et al proposed a shower affidavit strategy under vacuum for readiness of smooth polymer thin movies [5]. A similar creator moreover revealed arrangement of 
MEH-PPV:C60 polymer sun powered cell by a similar strategy [6]. Creation of OSC utilizing ultrasonic splash strategy was first announced by a gathering at National Renewable Energy Laboratory, USA [7]. Multi-source enhance with Photoshop splash covering was utilized to store rotating yet interpenetrating donor:acceptor layers, in a way like layer-by-layer statements, recommending that splash covering beginning from two autonomous arrangements is a reasonable alternative for film testimony [8]. Exceptionally as of late Jeffrey G. Tait et al provided details regarding concurrently pumped ultrasonic splash covering for donor: acceptor and thickness improvement of natural sun oriented cells [9]. Following Table 2 gives proficiency correlation of overall sunlight based cells created by shower covering process:

\section{MERITS OF DUAL LIQUID FEED}

In the single liquid nourish splash strategy both the materials (contributor and acceptor) are personally blended and disintegrated in the single dissolvable. The blended arrangement is showered on the substrate and amid hardening process prompting slight film, the contributor and acceptor may get stage isolated. In any case, as expressed prior, this stage detachment isn't finished and we get giver rich and acceptor rich spaces. To get better control over stage partition analysts have attempted expansion of some added substance solvents in the base arrangement. In the proposed double fluid sustain alternative we can break down the contributor and acceptor materials in two distinct solvents or independently in the same dissolvable. The two arrangements are then encouraged to two separate arrangement bays accessible in the duel fluid bolster ultrasonic spout. Accordingly, both the materials are just permitted to be in contact of each other at the tip of the ultrasonic spout, which keep the close blending of the two parts. The micrometer estimated drops created are conveyed towards the substrate with the assistance of bearer gas and get stored on the substrate. This structures the better and all around associated unadulterated periods of giver and acceptor material, which gives the nonstop way to the separated electrons and openings to reach relating cathodes. In this examination, we chose to manufacture the dynamic layer utilizing the Duel Liquid Feed Ultrasonic Nozzle in following three ways.

\section{EXPERIMENTAL SETUP}

Experimental arrangement of dual liquid feed ultrasonic spray system is as shown in the schematic representation in 
Figure 3.

\section{Fabrication of duel liquid feed ultrasonic nozzle on P3HT: PCBM Films.}

Using oxygen plasma for Patterning of the ITO substrate and transferred to chamber for treatment purpose. One of the important stages is cleaning of glassware and substrates due the any contamination or blemishes on a substrate straight influence the performance of device. Preparation of the solutions (P3HT and PCBM). In this present research work $2.23 \mathrm{mg}$ of $\mathrm{P} 3 \mathrm{HT}$ is liquefied in $1 \mathrm{ml}$ of the solvent, it has remained for rousing for 24 hour. Correspondingly 2.25 $\mathrm{mg}$ of PCBM is liquefied in $1 \mathrm{ml}$ of the solvent and the solution is stayed for rousing for 24 hour. When P3HT solution completed stirring, it has filtered with PTFE filter. The PTFE filter have pore size $0.25 \mathrm{vvm}$ to make sure the elimination of solute crystals from the solution. Using ultrasonication to $p$ PCBM solution in ultrasonic bathtub for concerning one hour, it has filtered the solution with PTFE $0.25 \mu \mathrm{m}$ filter previous to deposition. The fluid pumps have been used to feed both filtered solutions for additional deposition. It has adjusted both Solution flow rates on $10 \mathrm{ml} / \mathrm{hr}$, with $1 \mathrm{sec}$ ON time and 4 seconds and after that it is gives OFF time both the fluid pumps. When it is start to use Nitrogen Air flow on heater the substrate heater is give $\mathrm{ON}$, further the temperature of hot plate obtains steadied under the transporter gas flow. The nitrogen flow rate is preserve $81 \mathrm{pm}$. It is Annealed the PEDOT:PSS coated ITO for ten minute previous to deposition. At end it is always glass/ITO slides on hot plate for deposition and stay few minutes for temperature steadiness.

\section{MOBILITY MEASUREMENT}

The benefactor and acceptor stages in the dynamic layer of natural photovoltaic sun powered cell gadgets demonstrate significant change in opening and electron portability. The opening versatility $10-9 \mathrm{~m} 2 \mathrm{~V}-1 \mathrm{~s}-1$ of P3HT and electron portability 10-8 m2V-1s1 of PCBM has been announced, which indicates ten a request of distinction in electron and gap versatility of the materials. As often as possible utilized apparatus for researching charge bearer mobilities of low portability media is to inspect the spacecharge-restricted current through a semiconductor in the $\operatorname{dim}[10,11]$. Since the SCLC is specifically relative to the chargebearer portability [12]:

$$
\mathrm{j}_{\text {sclc }} \frac{9}{8} \varepsilon \mu \frac{2 \mathrm{~V}}{3_{\mathrm{L}}}
$$

Where $\varepsilon$ denotes the dielectric constant of material. $\mathrm{V}$ denotes the internal voltage of the device and $\mu$ is mobility charge 
carrier. On the off chance that lone the reliance of the charge bearer versatility on the electric field is taken into account, the SCLC is given by

$$
j_{\text {Dark }}=\frac{9}{8} \varepsilon \mu_{0} \exp 0.89 \gamma \frac{\overline{\mathrm{v}}}{\mathrm{L}} \frac{\mathrm{v}^{2}}{\mathrm{~L}^{3}}
$$

Where $\mathrm{V}$ denote applied voltage

$\mathbf{V}=\mathbf{V}_{\text {bias }}-\mathbf{V}_{\mathbf{b i}}-\mathbf{V}_{\mathbf{R s}}$

Where $V_{b i a s}$ is applied voltage $V_{b i}$ and

the $V_{R s}$ is drop voltage. And $V_{\text {bias }}$ and $V_{R s}=0$

The experiment data has been evaluated by using all mobility measurement with eq 2 . It is use to measure whole mobility in P3HT ITO/ PEDOT: PSS/ P3HT: PCBM/Au structure has been employed as the hole only device similar structure has been modified in present study. The schematic of device structure which was used for measurement of whole mobility displays in figure 4 .

The equation (2) was used to $\mathrm{f}$ fitted the experimental data. The e values are denoted field activation factor and $\mathrm{m}$ values are mobility. The experimental data have been fitted by using software ORIGIN. Figure 5, 6 and 7 demonstrate the results data which obtained by fabrication in P3HT: PCBM using Mobility measurement.

All fabrication was done by using mobility measurement and it has been used to calculated values of mbblity hole. Table 1 shows the results obtained from mobility measurement. Devices arranged utilizing chlorobenzene solvent shows increment in the gap portability because of expanded crystallinity of $\mathrm{P} 3 \mathrm{HT}$ in the movies. Be that as it may, in other two cases P3HT has been disintegrated in dichlorobenzene solvent. It is accounted for before that the dichlorobenzene solvent enhances the crystallinity of P3HT in the film. Accordingly for the devices with P3HT broken down in dichlorobenzene, the whole mobility is high without toughening the movies. It can be seen from the table that the mobility value is surprisingly better than that for toughened films with P3HT broke down in chlorobenzene. In addition, the gap mobility value is higher for the situation where (P3HT in dichlorobenzene + PCBM in chlorobenzene) mix is utilized than the situation where both P3HT and PCBM are disintegrated in normal dichlorobenzene dissolvable. This might be because of probability of more unadulterated stage arrangement in previous case (because of confined miscibility of two solvents) than the later. Diminishing in versatility in DD and CD structure in the wake of toughening however needs further examining.

\section{UV- SPECTROSCOPY}

Optical assimilation of P3HT is extremely touchy to changes in nearby 
condition and atomic course of action of P3HT particles and can be translated utilizing the Spano model of week after week collaborating H-totals $[15,16]$. As per this model, the proportion of the $0-0 / 0-1$ vibronic advances (at $\sim 595$ and $\sim 550 \mathrm{~nm}$, separately, see (Fig. 7)) can be identified with the size of total and, therefore intermolecular coupling inside the framework. Moreover, the disarranged polymer fastens offer ascent to a higher vitality, bring down wavelength, $\lambda$, assimilation (at $\lambda<540 \mathrm{~nm}$ ). Following figures demonstrates the retention spectra for the mix films kept with CC, DD and CD frameworks.

Table 2 shows Parameters of absorption spectra. It is investigated that all the blend films, a red shift in the amalgamation peak is watched. Increasing in efficient conjugation length of P3HT and increased collective of P3HT in the blend films is attributed red shift to head-to-tail linkages in the polymer sequence. The ratio of 0-0/0-1 vibronic transitions is displayed shoulder located at $600 \mathrm{~nm}$. It has been observed as a spectral feature of crystalline P3HT. It is assigned shoulder at 600 to an inter-chain excitation. Consequently, it can be obviously observed that the as deposited films with various different solvents demonstrate superior crystalline nature of P3HT. This has reflected in higher whole mobility value in mass heterojunction made with various solvents for the contributor and acceptors. At the point when same dissolvable is utilized for the affidavit of P3HT and PCBM mix, (fig.8 and 9) the likelihood of blending the giver and acceptor stage amid thin film development is more. This is on the grounds that miscibility of an indistinguishable dissolvable from well as nearly measure up to vanishing rates for the P3HT and PCBM arrangement drops. As both the materials are get blended it demonstrates smothered $0-0 / 0-1$ assimilation proportion which shows poor people total of polymer chains. On toughening the mix films, polymer gets requested what's more, brings about improvement in 0-0/0-1 assimilation highlight. Be that as it may, when we utilize the diverse solvents for P3HT and PCBM materials, the likelihood of their intermixing is less because of two reasons: less miscibility between the two solvents and unique dissipation times of the two arrangement beads. This immiscibility of the two stages enhances the crystallinity of the P3HT polymer chains in the mix which can be plainly found in the UV-Visible spectroscopy comes about (fig. 10). Because of low miscibility of both the solvents in 
each other P3HT frames requested structure in the film which upgrades the $0-0 / 0-1$ retention. After strengthening the general crystallinity moves forward which demonstrates lessened retention in the short wavelength locale. The fullerene retention around $\sim 340 \mathrm{~nm}$ is lessened on strengthening. This has been credited to the expanded area size of PCBM [20].

\section{OPTICAL MICROSCOPE IMAGES}

From the optical microscope images observed that the level of intermixing of the giver and acceptor stages is more in dichlorobenzene-dichlorobenzene framework than that in chlorobenzen-echlorobenzene framework. Giver and acceptor areas shaped in various dissolvable framework i.e. dichlorobenzene-chlorobenzene framework are substantially bigger when contrasted with the two indistinguishable dissolvable frameworks. This might be the consequence of various vanishing rates of the two solvents favoring convert the level of intermixing of the giver and acceptor stages is more in dichlorobenzene-dichlorobenzene framework than that in chlorobenzen-echlorobenzene framework. Giver and acceptor areas shaped in various dissolvable framework i.e. dichlorobenzene-chlorobenzene framework are substantially bigger when contrasted with the two indistinguishable dissolvable frameworks. This might be the consequence of various vanishing rates of the two solvents favoring favoring converging of consequent beads prompting arrangement of bigger spaces Figure 11. Display performance of chlorobenzene- chlorobenzene, dichlorobenzenedichlorobenzene and chlorobenzenedichlorobenzene solvents using Optical microscope images. 
Table 1: Comparative chart for all solvent combination

\begin{tabular}{|c|c|c|c|c|}
\hline Device Name & \multicolumn{2}{|c|}{ Solvent } & Annealing time (min) & Mobility (m2V-1s-1) \\
\hline & P3HT & PCBM & & \\
\hline & Chlorobenzene & Chlorobenzene & & \\
\hline CCA & & & 0 & $3.85 E-08$ \\
\hline CC10 & & & 10 & $1.84 E-07$ \\
\hline & Chlorobenzene & Chlorobenzene & & \\
\hline DDA & & & 0 & $1.22 E-07$ \\
\hline CDA & Dichlorobenzene & Chlorobenzen & 10 & $\mathbf{8 . 0 5 E - 0 8}$ \\
\hline CD10 & & & 0 & $2.64 E-07$ \\
\hline
\end{tabular}

Table 2: Gives vibronic transitions, the peak positions and the peak intensities using UV-Visible

\begin{tabular}{|c|c|c|c|}
\hline Name of simple & Transitions ratio of 0-0/0-vibronic & Position Peak & Intensity Peak \\
\hline CCA & $\mathbf{0 . 5 1 3 7 9}$ & 454 & 1.67 \\
\hline CC10 & $\mathbf{0 . 7 1 8 1 2}$ & 476 & 1.21 \\
\hline DDA & $\mathbf{0 . 4 2 8 7 5}$ & 462 & 1.74 \\
\hline DD10 & $\mathbf{0 . 5 6 7 7 1}$ & 472 & 1.38 \\
\hline DDA & $\mathbf{0 . 5 4 4 0 2}$ & 464 & 1.57 \\
\hline CD10 & $\mathbf{0 . 7 2 8 6 3}$ & 488 & 1.19 \\
\hline P3HT C & $\mathbf{0 . 6 7 6 6 4}$ & 522 & 1.03139 \\
\hline P3HT D & $\mathbf{0 . 6 1 0 8 7}$ & 514 & 1.06819 \\
\hline
\end{tabular}

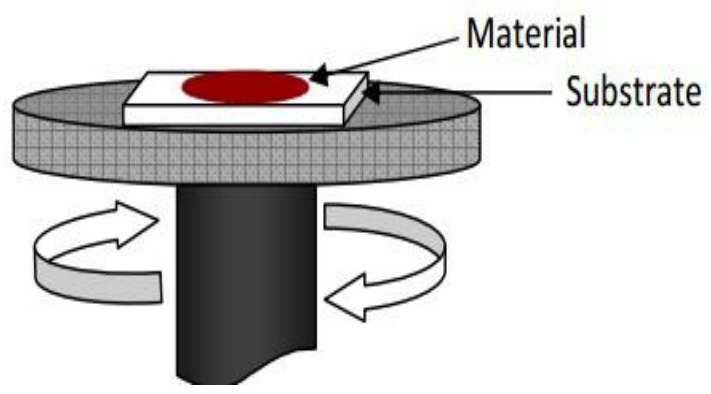

Figure:- 1: Schematic of spin coating approach

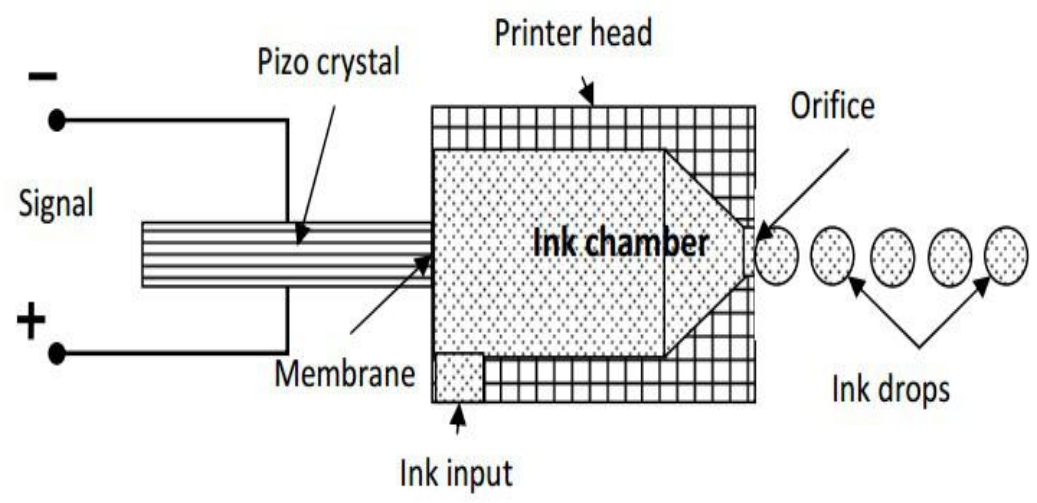

Figure 2: Schematic of inkjet printer head diagram 


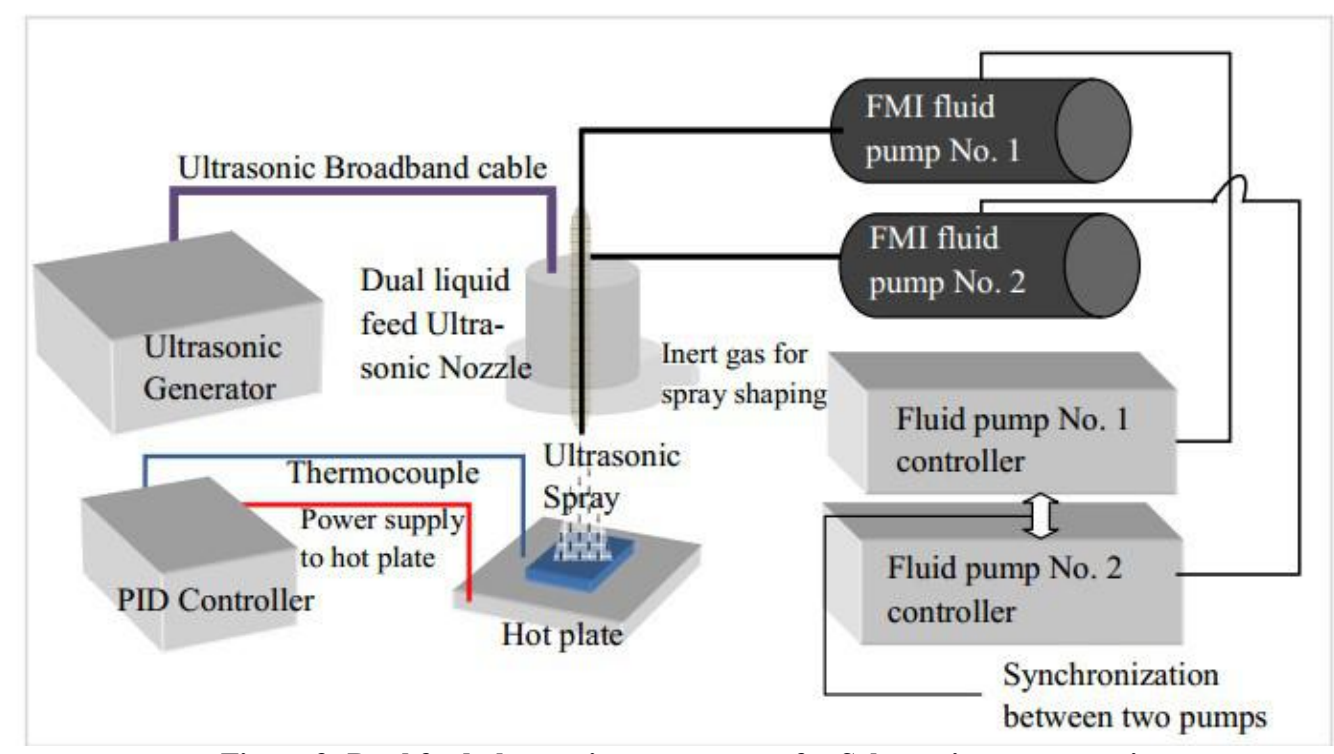

Figure 3: Dual feed ultrasonic spray system for Schematic representation

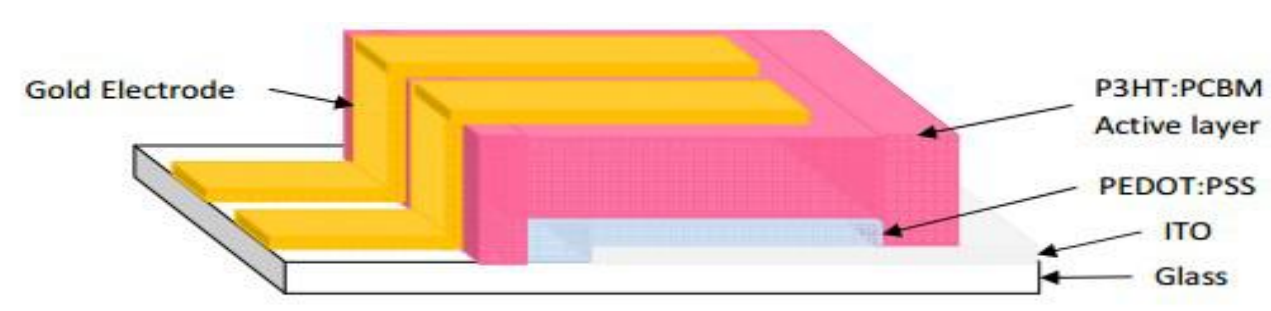

Figure 4: Device structure for mobility measurement

(a)

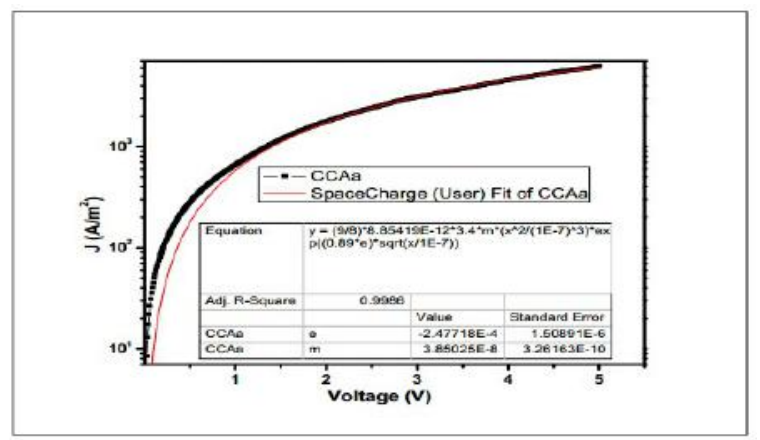

(b)

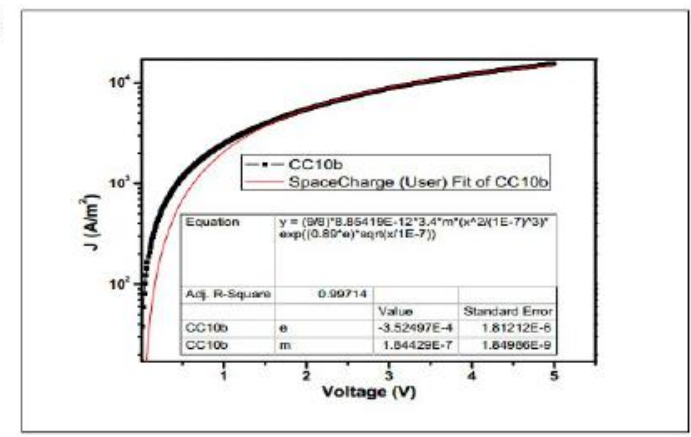

Figure 5: Display the performance of chlorobenzene solvent for the P3HT: PCBM blend films using Hole mobility measurements 
(a)

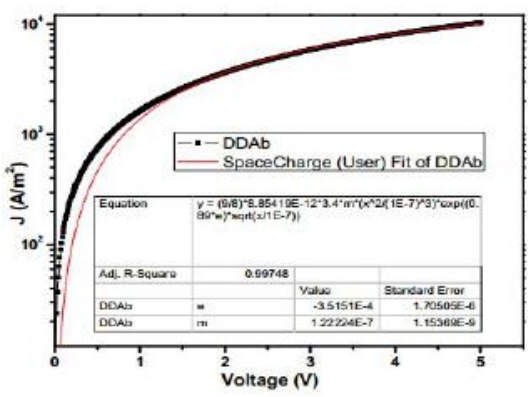

(b)

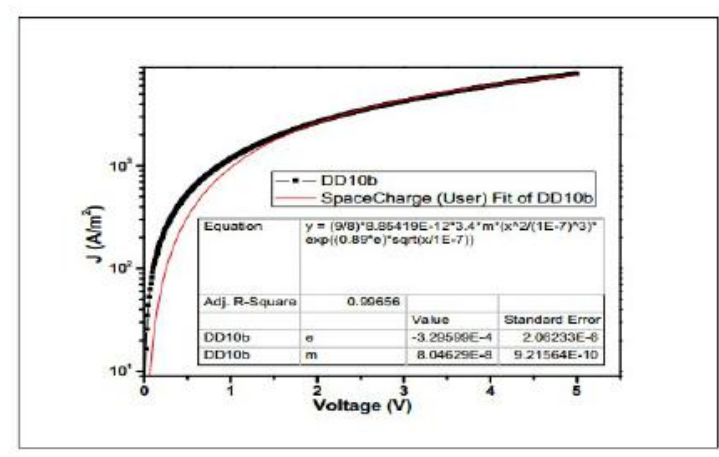

Figure 6: Display the performance of dichlorobenzene solvent for the P3HT: PCBM blend films using whole mobility measurements

(a)

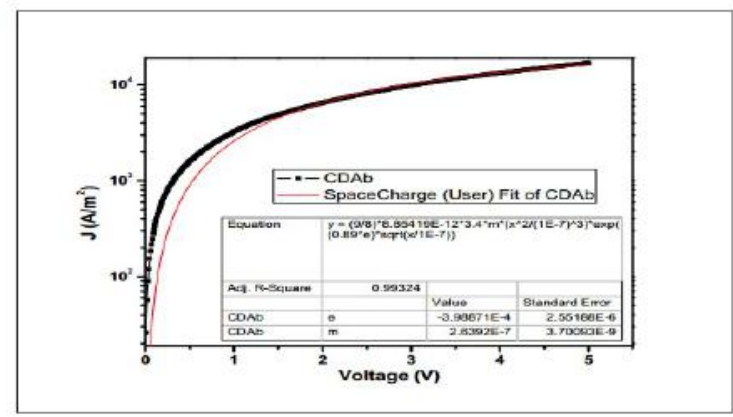

(b)

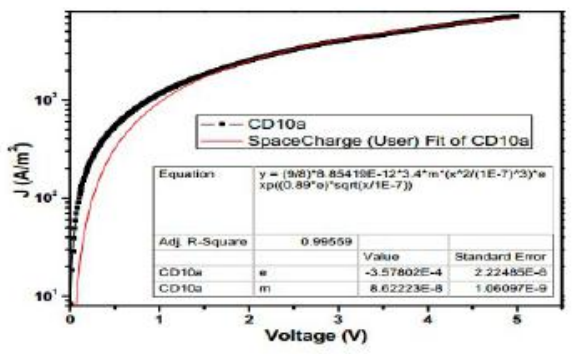

Figure 7: Display the performance of chlorobenzene solvent and PCBM in dichlorobenzene solvent for the P3HT:PCBM blend films using hole mobility measurements

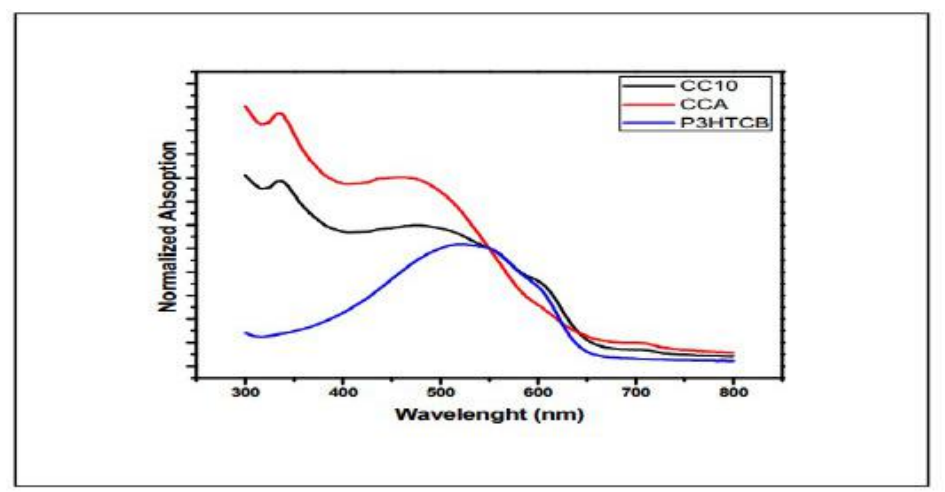

Figure 8: Display the performance of chlorobenzene solvent UV-Visible absorption for P3HT and PCBM blend using UV-Visible absorption 


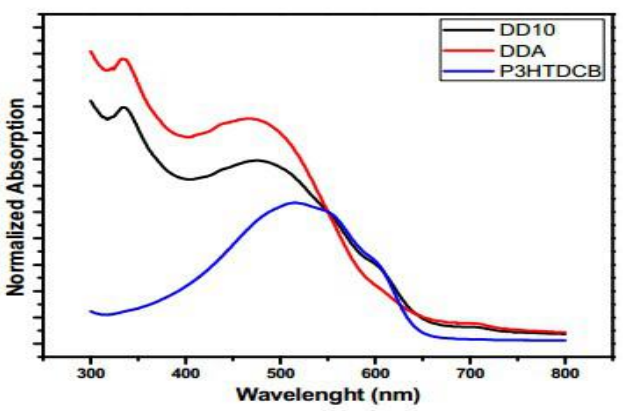

Figure 9: Display the performance of dichlorobenzene solvent UV-Visible absorption for P3HT and PCBM blend using UV-Visible absorption

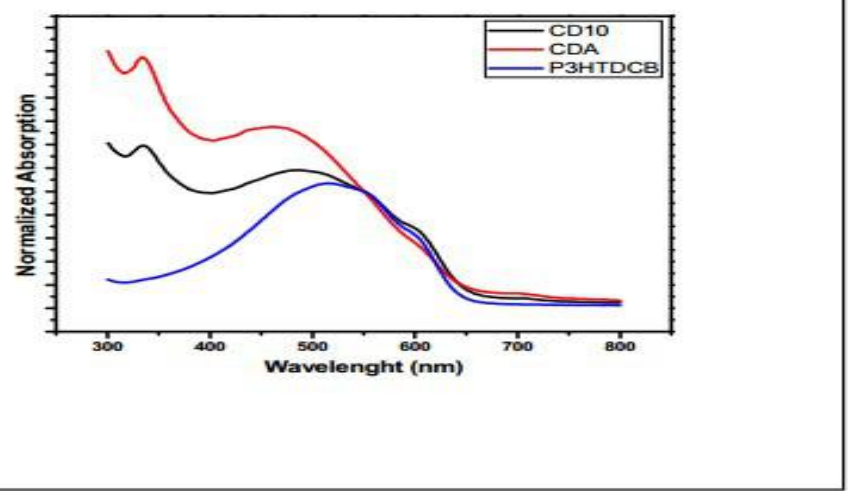

Figure 10: Display the performance of dichlorobenzene and PCBM in chlorobenzene solvent UV-Visible absorption for P3HT and PCBM blend using UV-Visible absorption

(a)

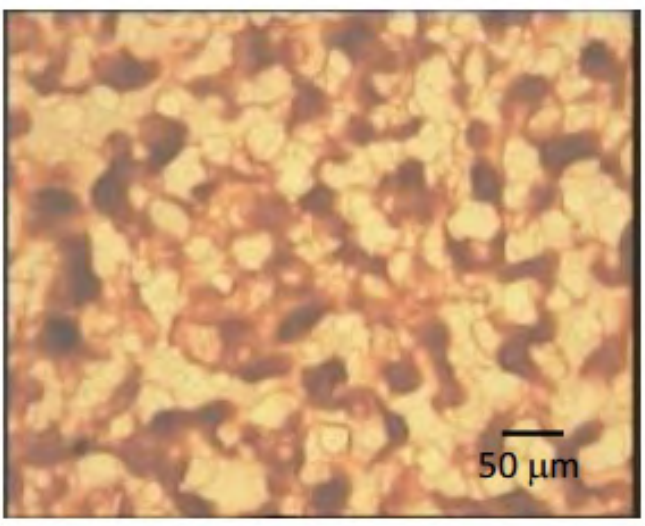

(b)

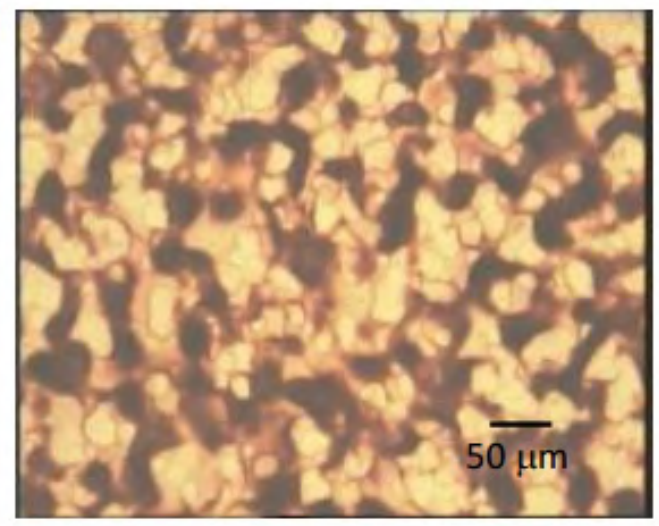


(e)

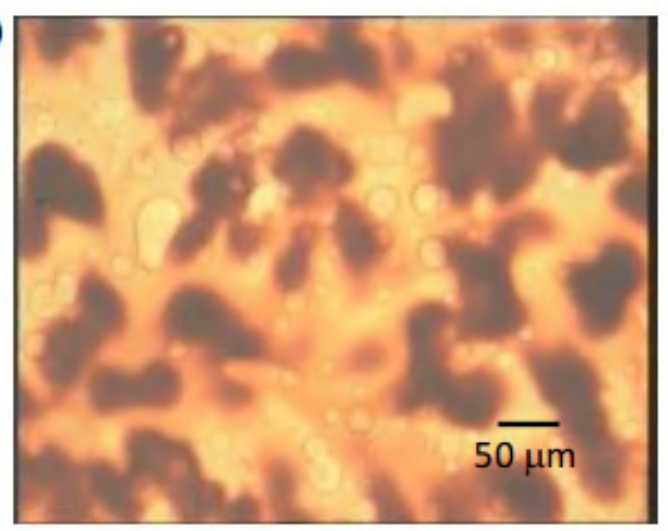

(c)

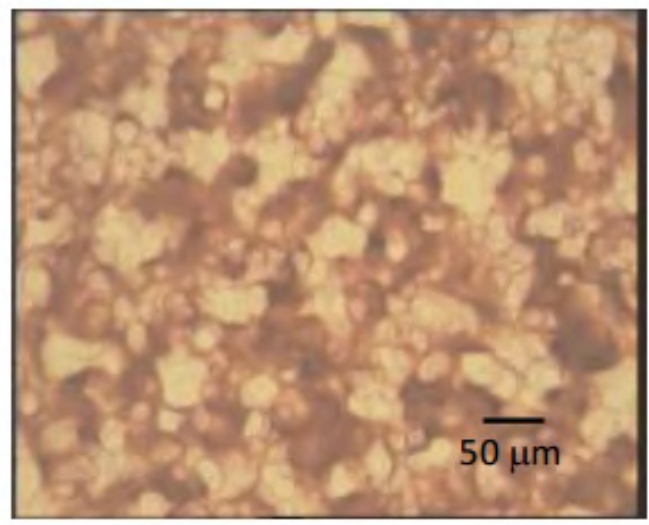

(f)

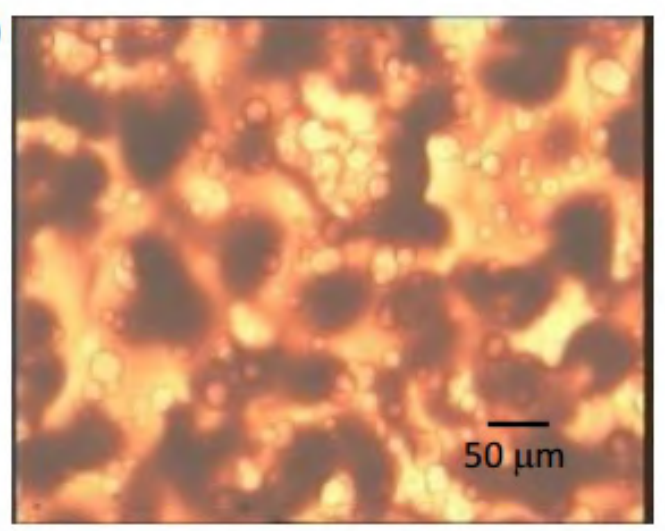

(d)

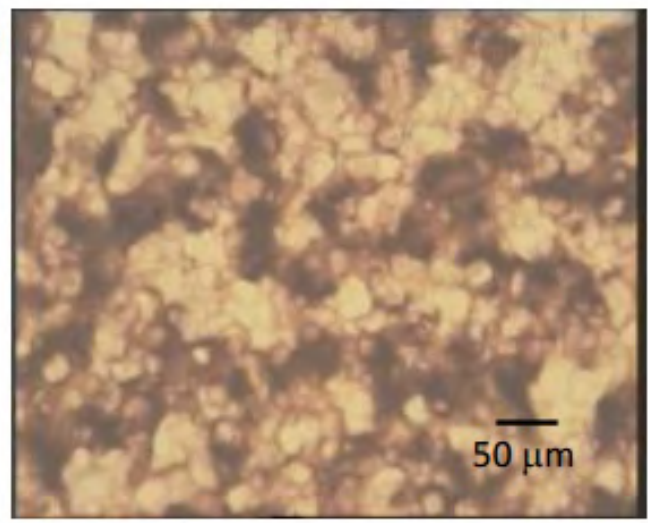

Figure 11: Display performance of chlorobenzene-chlorobenzene solvent (a), dichlorobenzene- dichlorobenzene solvent (b) and chlorobenzene- dichlorobenzene solvent (c) using Optical microscope images at centre of deposition area -20x zoomed.

\section{CONCLUSION}

The dual fluid encourages ultrasonic technique has been effectively shown for manufacture of P3HT: PCBM dynamic layer affidavit. Utilization of various solvents for the contributor and acceptor stages prompts better nature of the dynamic layer. Favorable position of utilizing distinctive solvents is plainly found as far as quality of stage detachment of the two stages reflected in better PL extinguishing furthermore, optical pictures. The thought that the novel duel fluid sustain technique should prompt unadulterated stage arrangement has been affirmed through AFM stage picture.

\section{REFERENCES}

[1] Okimoto H, Takenobu T, Yanagi K, Miyata Y, Shimotani H, Kataura H, Iwasa Y. Tunable Carbon Nanotube Thin-Film Transistors Produced Exclusively via Inkjet Printing. Advanced materials. 2010; 22(36): 3981-6.

[2] Steirer KX, Berry JJ, Reese MO, van Hest MF, Miedaner A, Liberatore MW, Collins RT, Ginley DS. 
Ultrasonically sprayed and inkjet printed thin film electrodes for organic solar cells. Thin Solid Films. 2009; 517(8): 2781-6.

[3] Echigo T, Naka S, Okada H, Onnagawa H. Spray method for organic electroluminescent device fabrication. Japanese journal of applied physics. 2002; 41(10R): 6219.

[4] Fujita K, Ishikawa T, Tsutsui T. Novel method for polymer thin film preparation: Spray deposition of highly diluted polymer solutions. Japanese journal of applied physics. 2002; 41(1A): L70.

[5] Mo X, Mizokuro T, Mochizuki H, Tanigaki N, Hiraga T. Preparation of smooth polymer thin film using spray method under vacuum. Japanese journal of applied physics. 2004; 43(1R): 307.

[6] Mo X, Mizokuro T, Mochizuki H, Tanigaki N, Hiraga T. Polymer solar cell prepared by a novel vacuum spray method. Japanese journal of applied physics. 2005; 44(1S): 656 .

[7] Steirer KX, Reese MO, Rupert BL, Kopidakis N, Olson DC, Collins RT, Ginley DS. Ultrasonic spray deposition for production of organic solar cells. Solar Energy Materials and Solar Cells. 2009; 93(4): 447-53.

[8] Chen LM, Hong Z, Kwan WL, Lu CH, Lai YF, Lei B, Liu CP, Yang Y. Multi-source/component spray coating for polymer solar cells. Acs Nano. 2010; 4(8): 4744-52.

[9] Tait JG, Rand BP, Heremans P. Concurrently pumped ultrasonic spray coating for donor: acceptor and thickness optimization of organic solar cells. Organic Electronics. 2013; 14(3): 1002-8.

[10] http://www.sono-tek.com

[11] http://en.wikipedia.org/wiki/Optical microscope

[12] Vak D, Kim SS, Jo J, Oh SH, Na SI, Kim J, Kim DY. Fabrication of organic bulk heterojunction solar cells by a spray deposition method for low-cost power generation. Applied Physics Letters. 2007; 91(8): 081102.

[13] Chen LM, Hong Z, Kwan WL, Lu CH, Lai YF, Lei B, Liu CP, Yang Y. Multi-source/component spray coating for polymer solar cells. Acs Nano. 2010; 4(8): 4744-52.

[14] Girotto C, Moia D, Rand BP, Heremans P. High-performance organic solar cells with spray-coated 
hole-transport and active layers. Advanced Functional Materials. 2011; 21(1): 64-72.

[15] Steirer KX, Berry JJ, Reese MO, van Hest MF, Miedaner A, Liberatore MW, Collins RT, Ginley DS. Ultrasonically sprayed and inkjet printed thin film electrodes for organic solar cells. Thin Solid Films. 2009; 517(8): 2781-6.

[16] Steirer KX, Reese MO, Rupert BL, Kopidakis N, Olson DC, Collins RT, Ginley DS. Ultrasonic spray deposition for production of organic solar cells. Solar Energy Materials and Solar Cells. 2009; 93(4): 44753.

[17] Tait JG, Rand BP, Heremans P. Concurrently pumped ultrasonic spray coating for donor: acceptor and thickness optimization of organic solar cells. Organic Electronics. 2013; 14(3): 1002-8.

[18] Rispens MT, Meetsma A, Rittberger R, Brabec CJ, Sariciftci NS, Hummelen JC. Influence of the solvent on the crystal structure of PCBM and the efficiency of MDMO-PPV: PCBM 'plastic'solar cells. Chemical Communications. 2003; (17): 2116-8.
[19] Green R, Morfa A, Ferguson AJ, Kopidakis N, Rumbles G, Shaheen SE. Performance of bulk heterojunction photovoltaic devices prepared by airbrush spray deposition. Applied physics letters. 2008; 92(3): 17.

[20] Cheng P, Li Y, Zhan X. A DMFassisted solution process boosts the efficiency in P3HT: PCBM solar cells up to $5.31 \%$. Nanotechnology. 2013; 24(48): 484008. 